\title{
Trajectory of Language Choices- from Kuala Lumpur, Malaysia to New Delhi, India: a Case Study
}

\author{
Maya Khemlani David
}

London School of Clinical Hypnosis, Former Professor (Sociolinguistics), University of Malaya

\begin{abstract}
Arranged marriages are the norm in traditional Indian families. With the Sindhi community such arranged marriages result at times with Sindhi brides being transplanted in new territories, having to learn new languages in order to communicate with interlocutors in the new setting. We investigate language choices of a Malaysian Sindhi woman who married an Indian Sindhi and settled down in New Delhi in an extended family system. What is the dominant language choice of a transplanted woman in her new family over a period of thirty years? Is it the heritage language, the local languages, or an international language? This research using both Fishman's domain concept for analysing language choice in a number of domains and retrospective data of discourse in a number of settings, will not only determine the dominant languages used but also interview the subject to determine reasons for the choice of the languages. In this way both an etic and emic perspective is provided in this study.
\end{abstract}

\section{INTRODUCTION}

Earlier studies of language shift among the Malaysian Sindhi's (David, 2001) show that younger members of this speech community have shifted to English. Studies in other countries (Jakarta, Singapore, Hong Kong, and Manila) of the same speech community also show that they too have shifted away from their ancestral language.

This paper conducts a microscopic and diachronic study of a Malaysian Sindhi woman who because of the arranged marriages that still dominate in this community found herself relocated in New Delhi on her 29th birthday. Many Sindhi women who were bred and brought up in Malaysia find themselves in many parts of the world due to arranged marriages. Malaysian Sindhi women are found in Jakarta, Singapore, Hong Kong, Manila, Barcelona, London, Chile, St Martin etc. In the same way many Sindhi women from other parts of the world find themselves after marriage, settling down in Kuala Lumpur. They come from Cairo, Hong Kong, India, Singapore, Jakarta and Canada inter alia.

In the course of life such women being transplanted in new territories and localities and family circumstances must have had to make decisions regarding their language choices. What languages should they use with different members of their extended families and with new friends in such new settings?

The objective of this research is to trace the language choices over a period of thirty years of a Malaysian Sindhi woman, (MV) married to an Indian Sindhi and who relocated to New Delhi after marriage.

The research questions arising from this research objective are as follows:

- What was the dominant language used with mother-in-law?

- What was the dominant language used with father -in-law?

- What was the dominant language used with spouse?

- What was the dominant language used with spouse's brother and wife?

- What was the dominant language used with her children?

- What was the dominant language used with newly acquired friends in New Delhi?

- Did the dominant language with family members change over a period of thirty years?

International Journal of Research in Sociology and Anthropology (IJRSA) 


\section{Theoretical AND CONCEPTUAL CONSTRUCTS}

\subsection{The Study of Domains}

Fishman (1971) proposed the concept of domain for the study of multilingualism. He advanced that domains facilitate scholars to study connections between clusters of interaction and interlocutors in more concrete social situations. Domains tend to provide data for social behaviour. Domain according to Fishman is"... a socio-cultural construct abstracted from topics of communication, relationships and interactions between communicators and locales of communication in accord with the institutions of a society..." (Fishman1972:82). Family is one of those vital domains Fishman allocates special place to in his work as he argues that, "multilingualism often begins in the family and depended upon it for encouragement if not for protection" (Fishman, 1972: 82).

\subsection{Domain Analysis of Language Choice}

Language choice has been analysed from various perspectives-sociological,

Social-psychological and anthropological. The sociological approach subcategorizes people's behaviour of language choice. The social-psychological approach seeks to provide internal reasons such as an individual's psychological conditions and needs for making a language choice. Finally, the anthropological approach seeks for external factors that may include the value system and culture for adopting a particular language.

Since this study addresses the social approach drawn on Fishman's domain analysis, the social approach will be highlighted. Fishman (1964) proposes that one language may be more suitable and applicable in certain domains which could be a number of factors such as participant, location and topic. Usually the prestigious language is used in high domains whilst the vernaculars are used in the low domains.

Employing domain analysis in India, Parasher (1980) found that the family is the only domain where the low languages and the subject's native language and the languages other than English dominate. English, the high language remains dominant in high domains like government, education and employment, but also in the informal domains like friendship and neighbourhood domain.

\subsection{Determinants of Language Choice}

There are several factors which determine language choice. These include speaker's first language, community language, age, education, role-relationships, dominant language, social status, economic and social standing of the linguistic group and the neutrality of language ((Dumanig, 2007).

Social mobility, urbanization, industrialization, migration or modernity may give impetus to language shift. Pragmatic reasons can also influence language choices in a bilingual or multilingual environment where other languages are more dominant than a speaker's L1.For Sino-Indians in the metropolitan environment of Kuala Lumpur Malaysia, the English language appears to have taken priority as their new L1 because "English is the more pragmatic code as it grants the Sino-Indians social mobility, education and networking (David, 2008:230). David (2001) conducted a study of language choice of the Sindhis in Malaysia across generations. The findings suggest that the generation 1 maintains Sindhi in peer interaction while generation 2 and 3 have moved away from the ethnic language adopting English as a medium with their contemporaries.

\subsection{Language Accommodation}

Giles, Coupland and Coupland (1991) proposed their accommodation theory which suggests that speakers converge to their interlocutors' language, style or mode of speech and adjust their speech to the needs of their interlocutors.

\subsection{Translanguaging}

The term translanguaging is a relatively recent one used in line with code-switching in the literature. Translanguaging is similar to code-switching in that it refers to multilingual speakers' shuttling between languages in a natural manner.

\section{METHODOLOGY}

The methodology is triangulated and included interviews with MV and her family members so as to determine language choice in a number of settings and with a range of interlocutors. In order to ensure 
that the retrospective data provided by MV was accurate, interviews with members of her family also took place. Such validation is essential as often the language people think they have used does not concur with the views held by others. A number of visits to the research site were made in order to observe the languages used.

\section{FINDINGS}

MV was an English language teacher and the home language in Kuala Lumpur, Malaysia was dominantly English. MV's parents used mainly English and some Sindhi amongst themselves in the home domain and MV grew up in a dominant English speaking and partial Sindhi speaking setting. She completed her first degree in English literature and her readings were generally the Classics and Shakespeare. With her siblings, colleagues, friends and even members of the same speech community English was used.

At the age of 29, she had an arranged marriage and settled down in Delhi. She agreed to getting married to a person in India as he could communicate in fluent English.

As she got married into a joint Hindu family, she had to communicate with all members of her new family.

The language used with the Mother in law (MIL) was mainly Sindhi. MV says she had enough Sindhi to communicate and her MIL who was originally from Singapore had some English. MV often used a mixture of Sindhi and English to communicate with her MIL.

For example- MV would tell her MIL "Maa late theendus" (I will be late).

With her Father in law (FIL), she used more English interspersed with some Sindhi words as he was a businessman who had a shop in a tourist area and therefore used English with his clients.

For example - When there were customers, MV would refer to the customers and tell her FIL that "they want to look at a few gold items, Sambhaal jo" (Be careful).

The Sindhi word "Sambhaal Jo" was also used as a private language to exclude the customer from the advice being given to the FIL.

However with her spouse, though he would most of the times speak in Sindhi, MV would reply predominately in English with some Sindhi initially. But over time, living in the Sindhi dominant household she progressed using more Sindhi. The same applied to other members of the family including her brother- in law and sister in law.

For example- when the spouse said "Mukhe Beddo" Thai de" (Please fry an egg for me) MV would reply "should I make an omelette or full fry...."

Later she progressed to say the same in Sindhi" fullfry Thaya ya Omelette? "(Should I make a fullfry or Omelette?).

In the beginning she could only speak in English with the hawkers and neighbouring grocery shopkeepers and she recollected how difficult it was.

Therefore at times when she didn't know the Hindi lexical items for certain vegetables or other products, she pointed at the products, therefore she used the communicative strategy of non verbal communication.

Over time by hearing Hindi she acquired some lexical items in Hindi and used a mixture of Hindi and some English with them.

For example- MV would ask the Hawkers and shopkeepers " tum kitne mein deta hai?"(how much do you sell this for? )or "Aacha vegetables dena"( give good vegetables).

The correct form of saying this in Hindi would be "Aap kitne Mein doge?"(how much do you sell this for?).

Ideally common Delhiites would say"aachi Sabzi dena"

(Give good vegetables).

Noticeably MV would use the English word vegetables and not the Hindi word "Sabzi for them. 


\section{Maya Khemlani David}

MV has two daughters and she sent them to an English medium convent school as MV was a convent school product. With her children, she mainly communicated in English as MV was more comfortable with English and could hardly communicate in any Hindi. Her MIL communicated with the children mainly in English as she had picked up more English.

She could not make many friends in the neighbourhood household as they were mostly Punjabi families and predominantly spoke in Hindi and Punjabi.

Since she had joined her husband in the family business, it was equally hard for her to communicate with the business suppliers who also mostly spoke in Hindi. However since the shop was in a tourist area, she had customers from all over the world of whom many spoke fluent English and she enjoyed business and conversations with them.

Even today while discussing business or significant personal matters with her grown up daughters who are also involved in the family business, MV uses Sindhi as a private language to exclude comprehension by household help, suppliers and customers.

Today as a grandmother she speaks with her 7 year old granddaughter in a mixture of Hindi, Sindhi and English. She primarily uses English so that her granddaughter gets a better command of the English language as being in Delhi, the granddaughter's larger context is Hindi speaking. Her elder daughter encourages MV to speak and read more in English with her daughter. This is important to her elder daughter as there is a Paradigm shift towards the English language among the young urban Delhites.

However her granddaughter takes great delight in correcting some of MV'S Hindi spoken words and sometimes in fact teaches MV new Hindi words.

For example- when MV says "vegetable man Edhar aao"(vegetable man come here)

Her granddaughter will correct her and say "Sabzi wala edhar aao"

This would be the correct way to say it in Hindi.

For example- MV would say "sheva karo nani Ki"(render your help or service to your grandmother).

Her granddaughter would correct it and say it's not "sheva, it's Seva" Also interestingly, being mainly in Delhi and in a Hindi dominant environment MV has progressed in her fluency in Hindi over the years and is quite comfortable using Hindi now with her neighbours, household help, hawkers and suppliers though her terms of address are sometimes inappropriate because she misses the finer points of the Hindi language and culture.

For example- Elders and people with whom professional relationships are shared should be addressed using "Aap" but MV continues using "Tum" which is used for younger interlocutors.

\section{DisCUSSION}

Initially, to communicate with the husband, it is clear that there was a non-reciprocal language between the spouses because they both chose to communicate in the language they were most comfortable in. With her in-laws and other members of the family, she used a mixture of English and Sindhi, depending on the situation and the person she was communicating with.

Non-verbal communication and improper/broken Hindi was used as a tool to survive to basically communicate with the professional vendors, neighbours, hawkers and household help.

With time, MV acquired not only more Sindhi but also a lot of Hindi as a result of living in a predominantly Hindi environment and predominantly Sindhi home domain.

This was the only pragmatic way for MV to communicate with her personal, social and business interlocutors. The communication was now not only between Sindhi and English, but between Hindi, Sindhi and English and therefore multilingualism in the larger environment resulted in translanguaging.

One of the important reasons for also using more Sindhi was that Sindhi was used as a private language to exclude outsiders from understanding personal and business discourse.

Also, urbanisation resulted in English being used as a prestigious language in high informal domains amongst friends and higher social circles. 
MV'S social milieu has with time also progressed to use more of English as a means of communication with her social circles and therefore it has become more convenient for MV to fall back to her preferred language choice in which she has always been more comfortable.

Hence, modernity and globalisation has played a role in the greater use of the English language. As we note that the social-psychological and anthropological environmental played a significant role. In the process of accommodating, MV started using a mixture of all three languages i.e. Hindi, Sindhi and English to communicate. She used many communicative strategies including code mixing and non verbal communication.

\section{CONCLUSION}

The choice of language constantly changes depending on a number of variables. The change and language choice is more prominent and rapid in cases where individuals change locations and have to adjust and adapt with the interlocutors' for personal, professional and social reasons. This results in translanguaging.

With the world becoming a global village, the English language has become prominent amongst the urban Indians and its use is widespread. This helps in accommodation and assimilation in new settings as transplanted individuals can use a potpourri of languages. Translanguaging has become an important phenomenon in a multilingual environment.

\section{REFERENCES}

[1] Fishman, J. (1964) Language Loyalty in the United States: the Maintenance and perpetuation of non- English Mother tongues by American ethnic and religious groups. The Hague: Mouton

[2] Fishman, J. (1968) Readings in the Sociology of Language.De Gruyter:Mouton.

[3] Fishman, J. (1971) Advances in the Sociology of Language. The Hague:Mouton.

[4] Fishman, J. (1972) Language in Sociocultural Change.Stanford:Stanford University Press.

[5] David, M.K (2001). The Sindhis of Malaysia: a Sociolinguistic Account. London : Asean Academic Press.

[6] David, M.K (2008) Language choice of urban Sino- Indians Kuala Lumpur, Malaysia.Migracijske 24:3, 217-233.

[7] Dumanig, F. (2007). Language choice in Southeast Asian mixed marriages. MICOLLAC.

[8] Giles, H. Coupland, N. and Coupland, J.(1991). Accommodation theory, communication, context and consequence in H. Giles, J Coupland and N Coupland (Eds.) Contexts of Communication : Developments in Applied Sociolinguistics pp1-68. Cambridge Cambridge University Press.

[9] Parasher S.N. (1980) Mother- tongue English diglossia: A case study ofIndian bilinguals' English use. Anthropological Linguistics 22:4 pp 151-68. 